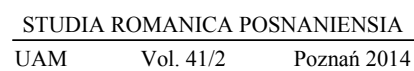

\title{
LIMBĂ
}

\section{TOMASZ CYCHNERSKI}

tomcych@amu.edu.pl

Uniwersytet im. Adama Mickiewicza, Poznań

\section{SINTAGMATICA MORFONOLOGICĂ A RADICALULUI FLEXIONAR NOMINAL: TIPURI DE STRUCTURĂ}

\begin{abstract}
Tomasz Cychnerski, Sintagmatica morfonologică a radicalului flexionar nominal: tipuri de structură [Morphonological syntagmatics of the nominal inflectional stem: structure types], Studia Romanica Posnaniensia, Adam Mickiewicz University Press, Poznań, vol. XLI/2: 2014, pp. 27-40. ISBN 978-83-232-2703-8. ISSN 0137-2475. eISSN 2084-4158. DOI: 10.7169/strop2014.412.003

This paper presents the results of a detailed analysis of the Roumanian nominal inflectional root. Its aim is to describe the morphonological types of root and their syntagmatic relevance. In this way, seven relevant types of the nominal inflectional root are defined according to its final phonological segments: unmarked vowel root, /u/ root, unmarked consonant root, /j/ root, consonant+liquid consonant root, palatal consonant root and velar consonant root.
\end{abstract}

Keywords: Roumanian, nominal inflection, morphonology, types of root, syntagmatic constraints

Comunicarea de faţă îşi propune să prezinte rezultatele analizei detaliate efectuate în domeniul sintagmaticii morfonologice a formelor flexionare nominale. Ea se înscrie, ca atare, într-un proiect mai mare întreprins de autor şi consacrat morfonologiei întregului sistem flexionar românesc. Bazele materiale şi principiile teoretice se limitează într-o mare măsură la lucrările indicate în bibliografie, pentru fonologia românei fiind ales sistemul propus de E. Vasiliu, iar pentru morfologie (flexiune) sistemul elaborat de V. Guțu Romalo. În amândouă sistemele folosite în analiza morfonologică au fost introduse însă unele modificări cu referire la poziţia în sistemul fonologic a câtorva tipuri de segmente, modificări privitoare la valorile categoriei de gen, dar mai ales cele unele se referă la detaliile analizei structurale a formelor flexionare înseși.

Mai departe, vor fi descrise toate tipurile morfonologice de radical flexionar nominal în funcţie de statutul fonologic al finalei lui. Mai întâi, vor fi prezentate tipurile de radical vocalic (deschis) şi, în al doilea rând, tipurile de radical consonantic (închis). Trebuie observat aici că în flexiunea nominală domină tipul închis de radical, radicalul vocalic caracterizând mai ales structura împrumuturilor 
noi. Pe de altă parte, în analiza întreprinsă a fost omisă structura morfonologică a radicalului considerat ca întreg, cât şi problema lungimii lui, pentru că relevantă la nivelul sintagmatic este numai finala.

\section{RADICAL VOCALIC}

Finala radicalului nominal poate fi orice unitate vocalică din întreg repertoriul fonemic. Vocala finală poate să fie accentuată sau neaccentuată. Ea poate să apară în această poziţie singură, constituind astfel un grup vocalic final simplu, sau poate să facă parte dintr-o secvenţă de vocale care formează împreună un grup vocalic final complex. La grupurile vocalice finale complexe, are relevanţă numai ultima vocală. Grupul vocalic final, cel simplu şi cel complex, este urmat la nominativ singular de o desinenţă realizată pozitiv sau negativ (Ø). Din punct de vedere morfonologic, în consecinţă şi din punct de vedere morfologic (flexionar), nu sunt relevante decât unele tipuri de radical vocalic. În rândurile ce urmează, vor fi descrişi radicalii nominali vocalici în funcţie de fiecare unitate vocalică tratată separat.

$$
\text { /i/ }
$$

Vocala finală /i/ poate apărea neaccentuată la substantive masculine (CULI), la substantive eterogene (PENALTI) şi la cele feminine (EFEBIE), sau accentuată la substantive masculine (BENGALI), la substantive eterogene (ALIBI) şi la cele feminine (BESTIE). La adjective ea apare la fel, fie accentuată (VIU, KAKI), fie neaccentuată (SEXY). În această poziţie ea nu formează niciodată grupuri complexe. La nominativ singular, segmentul/i/ este urmat de desinenţa -/e/ la substantive feminine (EFEBIE), de desinenţa -/w/ la adjective (VIU), şi de desinenţa - $\varnothing$ la cuvinte din toate clasele nominale. Exemple de radical terminat în /i/: kuli-, penalti-, efebi-, bengali-, alibi-, besti-, vi-, kaki-, seksi-.

$$
\mid \mathrm{i} /
$$

Vocala /it/ nu apare la finala substantivelor feminine. Ocurenţa ei este în fiecare caz marcată de accent: la substantive masculine (OSMANLÂU), la substantive eterogene (RÂU), şi la adjective (LĂLÂU). Ca şi vocala precedentă, ea nu formează grupuri complexe. La nominativ singular, vocala /ì/ se aşază numai înainte de desinenţa -/w/. Exemple de radical terminat în /it/: osmanli-, rit-, lalit-.

$/ \mathrm{u} /$

Segmentul vocalic final $/ \mathrm{u} /$ este mereu simplu, putând fi accentuat la substantive masculine (EMU), la substantive eterogene (ATU), la cele feminine (MORUĂ) şi la adjective (ACAJU) sau neaccentuat la substantive masculine (GURU), 
la substantive eterogene (REZIDUU), la cele feminine (INGENUǍ) şi la adjective (CONTINUU). La nominativ singular, vocala /u/ este urmată de desinenţa -/u/ la substantive eterogene şi la adjective, de desinenţa -/a/ la substantive feminine, şi de desinenţa - $\varnothing$, la substantive masculine, la cele eterogene şi la adjective. Exemple de radical terminat în /u/: emu-, atu-, moru-, akazu-, guru-, rezidu-, indzjenu-, kontinu-.

le/

Segmentul vocalic final /e/ este, la adjective, numai simplu, fiind totdeauna şi accentuat (GREU, BUCLE). La substantive, ca segment simplu, poate fi neaccentuat numai în clasa eterogenelor (ACVAFORTE), iar sub accent apare la substantive masculine (ATEU), la substantive eterogene (ESEU) şi la cele feminine (DIAREE). Spre deosebire de vocalele precedente, fonemul /e/ face parte din grupurile finale complexe: /oe/ la substantive eterogene (OENOCHOE) şi feminine (CANOE), şi /ie/ la substantive eterogene (PLIE). Vocala finală /e/ este urmată, la nominativ singular, de desinenţa $-/ \mathrm{w} /$ la substantive masculine, la cele eterogene şi la adjective, de desinenţa -/e/ la substantive feminine, iar de desinenţa - $\varnothing$ în toate clasele nominale. Exemple de radical terminat în /e/: gre-, bukle-, akfaforte-, ate-, ese-, diare-.

/o/

Vocala finală /o/, ca grup simplu, nu este accentuată numai la substantive feminine, în toate celelalte cazuri fiind ori accentuată: EROU (subst. masculin), CADOU (subst. eterogen), NOU (adjectiv), ori neaccentuată: PICOLO (subst. masculin), МОТО (subst. eterogen), IMAGO (subst. feminin), DISCO (adjectiv). Această vocală face parte şi din grupuri vocalice finale complexe: 1. /ao/ CALAO (subst. masculin), CACAO (subst. feminin); 2. /eo/ RODEO (subst. eterogen), METEO (adjectiv); 3. /io/ STUDIO (subst. eterogen), AUDIO (adjectiv); 4. /oo/ ZOO (subst. eterogen); 5. /uo/ DUO (subst. eterogen). La nominativ singular, finala prezentată aici poate fi urmată de desinenţa -/w/ la substantive masculine, la cele eterogene şi la adjective, iar de desinența - $\varnothing$ la cuvinte din toate clasele nominale. Exemple de radical terminat în /o/: ero-, kado-, no-, pikolo-, moto-, imago-, disko-.

$$
\text { /a/ }
$$

Finala vocalică /ə/ apare numai ca grup simplu şi numai sub accent la substantive masculine (CEAHLĂU), la substantive eterogene (RĂZĂLĂU) şi la adjective (RĂU). La nominativ singular, ea este urmată de desinenţa -/w/, iar, în mod excepţional, şi de desinența -Ø. Exemple de radical terminat în /ə/: tjaxla-, razalo-, rə-.

$/ \mathrm{a} /$

Vocala finală /a/ caracterizează toate clasele nominale, în care poate fi accentuată sau nu. Neaccentuată, ea apare la substantive masculine (LAMA), la substantive eterogene (TETRA), la cele feminine (LEVA), şi la adjective (GATA). Sub 
accent, ea este prezentă la substantive masculine (MACADAU), la substantive eterogene (CINEMA), la cele feminine (OCA), şi la adjective (LILA). În toate clasele nominale, această unitate face parte din grupul final complex - diftongul /ea/: ŞLEAU (subst. masculin), BLEAU (subst. eterogen), CAFEA (subst. feminin) şi ASEMENEA (adjectiv). Ca element al diftongului /oa/, ea se identifică numai în structura radicalilor substantiveli masculini (ANŞOA). Ca ultim element al grupului final complex /ia/, această finală apare la substantive masculine (PARIA), la substantive eterogene (MULTIMEDIA) şi la cele feminine (TIBIA). La substantive masculine de tipul BOA, vocala finală /a/ intră în compunerea grupului complex /oa/. La nominativ singular, este urmată de desinenţa -Ø în toate clasele nominale, şi de desinenţa $-/ \mathrm{w} /$ la substantive masculine. Exemple de radical terminat în $/ \mathrm{a} /$ : lama-, tetra-, leva-, gata-, makada-, tjinema-, oka-, lila-.

\section{RADICAL CONSONANTIC}

Radicalii nominali se pot termina cu aproape orice unitate consonantică din întreg repertoriul fonemic, cu excepţia unităţii /w/. Fonemul consonantic poate să stea în această poziţie singur, constituind astfel un grup consonantic final simplu, sau poate să facă parte dintr-o secvență de consoane care formează împreună un grup consonantic final complex. În grupurile consonantice finale complexe, are relevanţă ultima consoană; în unele cazuri şi sub unele condiţii, sunt relevante, însă, ultimele două consoane. Grupul consonantic final, cel simplu şi cel complex, este urmat la nominativ de o desinenţă realizată pozitiv (având forma unei vocale) sau negativ (fiind egală cu zeroul morfologic şi fonologic). Relevante din punct de vedere morfonologic, în consecinţă şi din cel morfologic (flexionar), sunt numai unele tipuri de radical consonantic. Mai departe, vor fi descrişi radicalii nominali consonantici în funcţie de fiecare consoană finală tratată aparte, consoanele înseşi împărţindu-se în patru tipuri: sonante (inclusiv semivocale), fricative, oclusive şi semioclusive.

$$
\text { /j/ }
$$

Radicalul terminat în $/ \mathrm{j} /$ este caracteristic pentru toate clasele de lexeme nominale. Segmentul $/ \mathrm{j} /$ postvocalic apare la substantive masculine (CRAI), la substantive eterogene (ULEI), la cele feminine (ODAIE), şi la adjective (GRIVEI). Această unitate fonologică intră uşor în compunerea grupurilor finale complexe bi-, şi chiar, trimembre. Clasa de lexeme cea mai săracă în radicali ce conţin grupul final complex bazat pe fonemul $/ \mathrm{j} /$ este clasa substantivelor feminine la care se identifică numai trei asemenea grupuri / rj/, /nj/ şi /tsj/: VINERI, LUNI, MARŢI. La adjective, se constată apariţia a şapte grupuri asemănătoare $/ \mathrm{dj} /, / \mathrm{bj} /, / \mathrm{tg} \mathrm{j} /, / \mathrm{nj} /, / \mathrm{pj} /$, $/ \mathrm{rj} /$, /prj/: MEDIU, AMFIBIU, LUCIU, STRANIU, CAPIU, POSESORIU, PROPRIU. La 
substantive masculine, avem deja de a face cu nouă asemenea grupuri $/ \mathrm{lj} /, / \mathrm{ftj} /, / \mathrm{t} \mathrm{j} \mathrm{j} /$, /ntjjj/, /ldj/, /dj/, /nj/, /rj/, /ntsj/: ULIU, PUŞTI, HARUSPICIU, NUNCIU, SOLDIU, RODIU, HIDRONIU, VERIGARIU, NUNȚIU. Cea mai bogată în grupurile finale complexe bazate pe segmentul $/ \mathrm{j} /$ este clasa substantivelor eterogene, la care se pot identifica chiar 39 de grupuri diferite: / $\mathrm{bj} / \mathrm{LABIU}, / \mathrm{mbj} / \mathrm{CAMBIU}, / \mathrm{rbj} / \mathrm{ERBIU}, / \mathrm{tg} \mathrm{jj} / \mathrm{CALCIU}, / \mathrm{nt} \mathrm{jj} /$ FRANCIU, /ndj/ INCENDIU, /rdj/ SARDIU, /rfj/ MORFIU, /cj/ BECHIU, /d $\mathrm{jj} /$ ADAGIU, /lḑ̧j/ SULGIU, /mj/ PREMIU, /lj/ DETALIU, /ftj/ CÂșTI, /vj/ FLUVIU, /rtsj/ CONSORȚIU, $/ \mathrm{t} \mathrm{jj} /$ EDIFICIU, /dj/ PALADIU, /nj/ CRANIU, /rj/ SCENARIU, /ntsj/ STRONȚIU, / $\mathrm{ksj} /$ PRAXIU, /zj/ GIMNAZIU, /nzj/ GERUNZIU, /dmj/ CADMIU, /lmj/ HOLMIU, /rmj/ FERMIU, /smj/ OSMIU, /fnj/ HAFNIU, /rnj/ CALIFORNIU, /pj/ MUNICIPIU, /trj/ NATRIU, /drj/ SINEDRIU, /brj/ MANUBRIU, /sj/ POTASIU, /tj/ LITIU, /gvj/ COLOCVIU, /tsj/ SPAȚIU, /ltsj/ CELŢIU. La nominativ singular, unitatea /j/ este urmată de desinenţele -/u/, -/e/ şi -Ø. Exemple de radical terminat în /j/: kraj-, ulej-, odaj-, grivej-.

$/ 1 /$

Radicalul terminat în $/ 1 /$ se identifică în toate clasele de lexeme nominale. Fonemul /1/ postvocalic este prezent la substantive masculine (CAL), la substantive eterogene (MAL), la cele feminine (BILĂ), şi la adjective (LOCAL). El constituie baza a trei grupuri finale complexe la adjective: /bl/ DUBLU, /pl/ TRIPLU, /mpl/ SIMPLU. La substantive masculine se pot găsi numai patru asemenea grupuri: /dl/ PUDL, /kl/ CIOCLU, /gl/ CULOGLU, /pl/ MULTIPLU. Mult mai bogate în grupuri asemănătoare sunt substantive eterogene şi feminine, la care se constată existența secvențelor: /k1/ CENACLU, FACLĂ; /bl/ CABLU, TABLĂ;/gl/ IGLU, RIGLĂ;/pl/ TRIPLU, ȚIPLĂ;/fl/ SUFLU, CHIFLĂ;/sl/ MASLU, ODRASLĂ;/vl/ NAVLU, DEVLĂ;/rl/ PERL, ȘARLĂ;/mbl/ ANSAMBLU, JIMBLĂ; /ngl/ EPENGLU, JUNGLĂ;/mpl/ TEMPLU, TÂMPLĂ; /j1/ EMAIL, TRAILĂ. La substantive eterogene apar în plus şi grupurile /tl/ TITLU, /nkl/ VINCLU, iar la substantive feminine grupurile /dl/ POVIDLĂ, /xl/ ȚÂHLĂ, /zl/ GUZLĂ. La nominativ singular, fonemul /1/ este urmat de desinenţele - $\varnothing,-/ \mathrm{u} /$, , -/e/ şi -/ə/. Exemple de radical terminat în /1/: kal-, mal-, bil-, lokal-.

$/ \mathrm{r} /$

Ca şi sonanta precedentă, unitatea $/ r /$ este ultimul segment al radicalului adjectival şi substantival din cele trei clase structurale (generice). După vocală, fonemul $/ \mathrm{r}$ / este prezent la substantive masculine (URSAR), la substantive eterogene (ZIAR), la cele feminine (BARĂ), şi la adjective (VULGAR). Sonanta discutată aici este elementul constitutiv al numeroaselor grupuri finale complexe, atât în cele trei clase generice ale substantivelor, cât şi la adjective. În cele patru clase de lexeme nominale apar grupurile următoare (exemplele sunt prezentate în ordinea „substantiv masculin, substantiv eterogen, substantiv feminin, adjectiv"): /br/ LABRU, CANDELABRU, ZEBRĂ, SOBRU; /mbr/ ZÂMBRU, MEMBRU, UMBRĂ, SUMBRU; /tr/ HANTRU, CENTRU, CONTRĂ, HÂTRU; /str/ ASTRU, CASTRU, GLASTRĂ, ALBASTRU; 
/kr/ ACRU, LUCRU, ICRĂ, ACRU; /dr/ CEDRU, CADRU, IDRĂ, ANHIDRU; /ndr/ LEANDRU, MEANDRU, TUNDRĂ, MÂNDRU. Grupurile /gr/ şi /kstr/ apar la substantive masculine şi feminine, cât şi la adjective: TIGRU, PODAGRĂ, NEGRU; AMBIDEXTRU (s.m.), AMBIDEXTRU (adj.), AMBIDEXTRĂ. Grupul /spr/ este prezent numai la substantive masculine şi la adjective: ASPRU, ASPRU. La substantive masculine, eterogene şi feminine, se pot identifica grupurile /tr/, /fr/ şi /vr/: PEDIATRU, TEATRU,

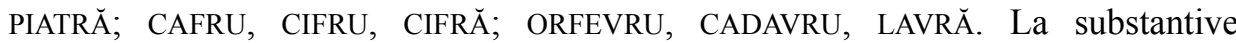
masculine şi eterogene apare grupul /ptr/: CATADIOPTRU, DIOPOTRU, la substantive masculine şi feminine grupul /skr/: CUSCRU, CUSCRĂ, la substantive eterogene şi feminine grupul /pr/: ŞOPRU, CAPRĂ. Numai la substantive eterogene apar grupurile $/ \mathrm{kr} /, / \mathrm{nkr} /, / \mathrm{ktr} /, / \mathrm{ltr} /, / \mathrm{rtr} /, / \int \mathrm{tr} /:$ SEPULCRU, ŞANCRU, SPECTRU, FILTRU, TEARTRU, MUŞTRU. Numai la substantive feminine sunt prezente grupurile /mr/ şi /jr/: DOMRĂ, CALDEIRĂ. La nominativ singular, fonemul /r/ este urmat de desinenţele -Ø, -/u/, -/e/ şi -/ə/. Exemple de radical terminat în /r/: ursar-, ziar-, bar-, vulgar-.

$/ \mathrm{m} /$

Segmentul final al radicalului având forma fonemului $/ \mathrm{m} /$ postvocalic caracterizează toate clasele de lexeme nominale: AVRAM (subst. masculin), NUME (subst. eterogen), TEAMĂ (subst. feminin), SUBLIM (adjectiv). La fel se comportă două grupuri finale complexe $/ \mathrm{lm} / \mathrm{şi} / \mathrm{rm} /$, în care elementul $/ \mathrm{m} /$ este precedat de o altă sonantă: PSALM, FILM, PALMĂ, CALM; VIERME, ŢĂRM, ARMĂ, ENORM (în ordinea respectivă). Grupurile finale complexe $/ 3 \mathrm{~m} /, / \mathrm{sm} / \mathrm{şi} / \mathrm{stm} /$ sunt prezente la substantive eterogene şi feminine: PREAJM, PREAJMĂ; BASM, MIREASMĂ; ASTM, ASTMĂ. Grupul /tm/ apare numai la substantive masculine şi eterogene (LOGARITM, RITM), iar grupul /jm/ numai la substantive masculine şi feminine (ŞOIM, FAIMĂ). Exclusiv la substantive feminine apar grupurile $/ \mathrm{dm} /, / \mathrm{gm} /, / \mathrm{xm} /, / \mathrm{gm} /, / \mathrm{zm} /$ : VIDMĂ, MAGMĂ, DRAHMĂ, CRIŞMĂ, CIZMĂ. La nominativ singular, fonemul $/ \mathrm{m} /$ este urmat de desinenţele -Ø, -/e/ şi -/ə/. Exemple de radical terminat în /m/: avram-, num-, team-, sublim-.

$/ \mathrm{n} /$

Sonanta nazală apare în poziţia postvocalică la sfârşitul radicalului din structura substantivelor masculine, eterogene şi feminine (MUEZIN, TREN, ANTENĂ) şi din cea a adjectivelor (SENIN). Asemănător cu unele grupuri finale complexe conţinând pe ultimul loc fonemul /m/, grupurile finale care se termină în $/ \mathrm{n} /$ au înaintea sonantei nazale o altă sonantă - /r/ sau /m/, grupul /rn/ fiind prezent la substantive masculine (CORN), la substantive eterogene (GUVERN), la cele feminine (IARNĂ), şi la adjective (MODERN), iar grupul /mn/, paralel, la substantive masculine (SOMN), la substantive eterogene (LEMN), la cele feminine (DOAMNĂ) şi la adjective (DEMN). Distribuţia celorlalte grupuri este mai limitată. Grupul /gn/ este prezent numai la substantive eterogene (REGN), la cele feminine (SAGNĂ) şi la adjective (BENIGN), grupul /jn/ la 
substantive masculine (CÂINE), la cele feminine (TAINĂ) şi la adjective (FAIN), iar grupul /vn/ numai la substantive masculine (CLOVN) şi feminine (RÂVNĂ). Alte nouă grupuri apar exclusiv la substantive feminine: $/ \mathrm{kn} /$ TICNĂ, /dn/ LOGODNĂ, /fn/ BUFNĂ, /xn/ ODIHNĂ, /3n/ PODOROJNĂ, /ln/ STOLNĂ, /sn/ PLEASNĂ, / $\mathrm{n} /$ CROŞNĂ, /zn/ POZNĂ. La nominativ singular, fonemul /n/ este urmat de desinenţele - $Ø$, -/e/ şi -/ə/. Exemple de radical terminat în /n/: muezin-, tren-, anten-, senin-.

/f/

Fonemul /f/, singur în poziţie postvocalică şi în grupurile complexe /lf/ şi /rf/, apare la sfârşitul radicalului substantival: masculin (ŞEF, ELF, ŞOVÂRF), eterogen (PRAF, GOLF, VÂRF) şi feminin (CEAFĂ, CALFĂ, MARFĂ), precum şi la sfârşitul radicalului adjectival (BUF, MONADELF, AMORF). Grupul final complex /mf/ caracterizează radicalul substantival masculin (REMF), eterogen (TRIUMF) şi feminin (LIMFĂ). Grupul /nf/ apare numai la adjective (FONF), grupul /jf/ numai la substantive eterogene (SSRAIF), iar singurul grup trimembru /rtf/ numai la substantive feminine (JERTFĂ). La nominativ singular, fonemul /f/ este urmat de desinenţele - $\varnothing$ şi -/ə/. Exemple de radical terminat în /f/: $\int e f-$, praf-, thaf-, buf-.

/v/

Fonemul /v/, singur în poziţie postvocalică şi în grupul complex /rv/, apare la sfârşitul radicalului substantival: masculin (ELEV, NERV), eterogen (EXPLOZIV, STÂRV) şi feminin (ŢEAVĂ, LARVĂ), precum şi la sfârşitul radicalului adjectival (GRAV, PELTINERV). Grupul final complex /lv/ caracterizează radicalul substantival masculin (TÂLV), feminin (SALVĂ) şi cel adjectival (BIVALV), iar grupul /dv/ caracterizează radicalul substantival masculin (MOLIDV) şi feminin (MOLIDVĂ). Grupul /gv/ apare numai la substantive feminine (TIGVĂ), singurul grup trimembru /ngv/ numai la adjective (BILINGV), iar singurul grup compus din patru consoane $/ \mathrm{rzdv} /$ numai la substantivul feminin DJURSTVĂ. La nominativ singular, fonemul /v/ este urmat de desinenţele - $\varnothing$ şi -/ə/. Exemple de radical terminat în $/ \mathrm{v} /$ : elev-, eksploziv-, tseav-, grav-.

$/ \mathrm{s} /$

Fonemul /s/, singur în poziţie postvocalică şi în grupurile complexe /ks/, /ns/ şi /rs/, apare la sfârşitul radicalului substantival: masculin (COCOS, INDEX, INS, URS), eterogen (ATLAS, PIX, DANS, MERS) şi feminin (CASĂ, AXĂ, ŞANSĂ, FARSĂ) şi la sfârşitul radicalului adjectival (TEPOS, FIX, STRÂNS, ADVERS). Grupul final complex /ps/ se identifică în structura radicalului substantival: masculin (BICEPS), eterogen (GHIPS) şi feminin (CAPSĂ), grupul /ls/ în structura radicalului substantival eterogen (VALS) şi în structura radicalului adjectival (SMULS), iar grupul/js/ în structura radicalului substantival eterogen (GNAIS) şi feminin (PARADAISĂ). Singurul grup trimembru /nks/ apare la substantive masculine (SFINX) şi eterogene (SIRINX). La 
nominativ singular, fonemul /s/ este urmat de desinenţele - $\varnothing$ şi -/ə/. Exemple de radical terminat în /s/: kokos-, atlas-, kas-, tsepos-.

$|\mathrm{z}|$

Fonemul /z/, singur în poziţie postvocalică şi în grupul complex /rz/, apare la sfârşitul radicalului substantival: masculin (OVĂZ, ORZ), eterogen (CAZ, ARZ) şi feminin (BAZĂ, VARZĂ) şi la sfârşitul radicalului adjectival (POLONEZ, DÂRZ). Grupul final complex /nz/ caracterizează radicalul substantival: masculin (MÂNZ), eterogen (PRÂNZ) şi feminin (PÂNZĂ). Grupul $/ \mathrm{mz} /$ caracterizează radicalul substantival masculin (NARAMZ) şi feminin (NARAMZĂ), grupurile /bz/ şi /jz/ radicalul substantival eterogen (CHIBZ, MELŞPAIZ) şi feminin (COBZĂ, GAIZE), iar grupul /lz/ - numai radicalul substantival masculin (SOLZ). La nominativ singular, fonemul /z/ este urmat de desinenţele - $\varnothing$ şi -/ə/. Exemple de radical terminat în /z/: ovaz-, kaz-, baz-, polonez-.

$$
\text { / } /
$$

Fonemul / $/ \mathrm{d} /$, singur în poziţie postvocalică apare la sfârşitul radicalului substantival masculin (LENEŞ), eterogen (DUŞ) şi feminin (MĂTUŞĂ) şi la sfârşitul radicalului adjectival (POZNAŞ). Grupul final complex /r $\mathrm{f} /$ caracterizează radicalul substantival masculin (PÂRŞ), eterogen (MARŞ) şi feminin (VÂRŞĂ), grupul /rj/ caracterizează radicalul substantival masculin (COMANŞ), feminin (PLANŞĂ) şi cel adjectival (ETANŞ), iar grupul /1 $\mathrm{j} /$ - numai radicalul adjectival (FALŞ). Grupurile $/ \mathrm{k} J /$, $/ \mathrm{p} \int /$ şi $/ \mathrm{j} \int /$ apar numai în structura radicalului substantival feminin (RICŞĂ, LEAPŞĂ, GHEIŞĂ). La nominativ singular, fonemul /J/ este urmat de desinenţele -Ø şi -/ə/. Exemple de radical terminat în $/ \mathrm{f} /$ : lenef-, duf-, matuf-, poznaf-.

\section{$\mid 3 /$}

Fonemul /3/, singur în poziţie postvocalică şi în grupul complex /nz/, apare la sfârşitul radicalului substantival masculin (CIOCLEJ, GÂNJ), eterogen (GARAJ, DERANJ) şi feminin (RUJǍ, ALONJĂ) şi la sfârşitul radicalului adjectival (GREJ, ORANJ). Grupul final complex /r3/ caracterizează radicalul substantival masculin (PERJ), eterogen (SERJ) şi feminin (MARJǍ). La nominativ singular, fonemul $/ 3 /$ este urmat de desinenţele - $\varnothing$ şi -/ə/. Exemple de radical terminat în /z/: tjoklez-, garaz-, ruz-, oranz-.

$$
\mid \mathrm{x} /
$$

Fonemul / $\mathrm{x} /$ singur în poziţie postvocalică apare la sfârşitul radicalului substantival masculin (ŞAH), eterogen (VĂZDUH) şi feminin (MAŞTEHĂ) şi la sfârşitul radicalului adjectival (VLAH). Grupul final complex /rx/ caracterizează radicalul substantival masculin (OLIGARH) şi feminin (ERHĂ), iar grupul /lh/ numai radicalul substantival feminin (SILHĂ). La nominativ singular, fonemul $/ \mathrm{x} /$ este 
urmat de desinenţele - $\varnothing$ şi -/ə/. Exemple de radical terminat în /x/: fax-, vazdux-, mafteh-, vlax-.

$$
/ \mathrm{p} /
$$

Radicalul nominal terminat în $/ \mathrm{p} /$ singur în poziţie postvocalică şi făcând parte din grupurile complexe $/ \mathrm{lp} /, / \mathrm{mp} /$ şi $/ \mathrm{rp} /$, se identifică la substantive masculine (LUP, STÂLP, GHIMPE, ŞARPE), la substantive eterogene (NISIP, SCALP, CÂMP, CARP), la cele feminine (CEAPĂ, TALPĂ, LAMPĂ, CÂRPĂ), şi la adjective (ŞCHIOP, CALP, TÂMP, MONOCARP). În plus, grupul final complex /sp/ caracterizează substantive masculine (OASPE), eterogene (JASP) şi feminine (PRISPĂ). Grupurile / $/ \mathrm{p} /$ şi /jp/ apar în această poziţie numai la substantive feminine (RAŞPĂ, TOAIPĂ). La nominativ singular, fonemul $/ \mathrm{p} /$ este urmat de desinenţele - $\varnothing,-/ \mathrm{e} /$ şi -/ə/. Exemple de radical terminat în /p/: lup-, nisip-, tjap-, fcop-.

$$
/ \mathrm{b} /
$$

Radicalul nominal terminat în /b/ singur în poziţie postvocalică şi făcând parte din grupurile complexe $/ \mathrm{lb} /, / \mathrm{mb} /$ şi $/ \mathrm{rb} /$, se identifică la substantive masculine (ROB, BULB, PLUMB, SÂRB), la substantive eterogene (ŞURUB, COLB, DÂMB, VERB), la cele feminine (BABĂ, HALBĂ, LIMBĂ, BARBĂ) şi la adjective (SLAB, ALB, STRÂMB, ORB). În plus, grupul final complex /jb/ caracterizează substantive eterogene (CUIB) şi feminine (ZGAIBĂ), precum şi adjective (ROIB). Grupurile /̧̧b/ şi /zb/ apar în această poziţie numai la substantive feminine (SLUJBĂ, IZBĂ). La nominativ singular, fonemul /b/ este urmat de desinenţele - $\varnothing,-/ \mathrm{e} /$ şi -/ə/. Exemple de radical terminat în /b/: rob-, furub-, bab-, slab-.

$$
/ \mathrm{t} /
$$

Radicalul nominal terminat în /t/, singur în poziţie postvocalică şi făcând parte din grupurile complexe /nt/, /st/, /lt/, /pt/, /rt/, /kt/ şi /nkt/, se identifică la substantive masculine (SOLDAT, DINTE, STAROSTE, ADULT, PIEPT, EXPERT, PREFECT, DEFUNCT), la substantive eterogene (MANDAT, GLONTE, TEST, ASFALT, LAPTE, SFERT, ACT, PUNCT) la cele feminine (REŢETĂ, GEANTĂ, NEVASTĂ, BALTĂ, LUPTĂ, CARTE, SECTĂ, DEFUNCTĂ) şi la adjective (MUIAT, URGENT, MODEST, ÎNALT, DREPT, CERT, EXACT, ADJUNCT). Grupurile finale complexe $/ \mathrm{st} /$ şi / ft/ caracterizează toate cele trei clase generice ale substantivelor (CLEŞTE, DEŞT, POŞTĂ; MOLIFT, RAFT, BAFTĂ), iar grupurile / $\mathrm{xt} /$, /jt/ şi /rst/ - numai substantive eterogene şi feminine (IAHT, ŞLEAHTĂ; HAIT, RAITĂ; TERMOCARST, VÂRSTĂ). Pe de altă parte, grupul final /kst/ caracterizează substativele eterogene şi feminine, precum şi adjective (TEXT; SIXTĂ; MIXT). Grupul final complex /mt/ apare numai la substantive eterogene (STRÂMT) şi la adjective (STRÂMT). Grupul / $\mathrm{frt} / \mathrm{determină} \mathrm{numai} \mathrm{substantive} \mathrm{masculine}$ (CRENVURŞT), grupul /rkt/ numai pe cele eterogene (INFARCT), grupurile $/ \mathrm{nst} / \mathrm{s} \mathrm{i} / \mathrm{p} \mathrm{ft} /$ numai pe cele feminine (CINSTE, OBȘTE), iar grupul /mpt/ determină numai 
adjectivele (PROMPT). La nominativ singular, fonemul /t/ este urmat de desinenţele -Ø, -/e/ şi -/a/. Exemple de radical terminat în /t/: soldat-, mandat-, retset-, mujat-.

$/ \mathrm{d} /$

Radicalul nominal terminat în /d/, singur în poziţie postvocalică şi făcând parte din grupurile complexe $/ \mathrm{ld} /, / \mathrm{nd} /$ şi $/ \mathrm{rd} /$, se identifică la substantive masculine (INDIVID, SCALD, BRIGAND, BARD), la substantive eterogene (ZID, ŞOLD, GÂND, ABSURD), la cele feminine (CADĂ, PILDĂ, BANDĂ, COARDĂ) şi la adjective (UMED, CALD, BLÂND, SURD). Grupurile finale complexe /zd/, / $/ \mathrm{d} / /$ şi /jd/ caracterizează substantive eterogene şi feminine (GHIZD, GRAJD, RAID; BRAZDĂ, NĂDEJDE, GAIDĂ), grupul /gd/ caracterizează numai substantive eterogene (SMARAGD), iar grupul /bd/ numai substantive feminine (LOBDĂ). La nominativ singular, fonemul /d/ este urmat de desinenţele -Ø, -/e/ şi -/ə/. Exemple de radical terminat în /d/: individ-, zid-, kad-, umed-.

$/ \mathrm{c} /$

Fonemul /c/ cu care se termină radicalul nominal apare mai ales singur în poziţie postvocalică la substantive masculine (OCHI), la substantive eterogene (ICHI), la cele feminine (PERECHE) şi la adjective (VECHI). Foarte puţine grupuri finale complexe $/ \int \mathrm{c} / \mathrm{şi} / \mathrm{nc} /$ caracterizează substantive masculine (MUŞCHI, GENUNCHI), ultimul grup apărând şi la substantive eterogene (MĂNUNCHI). La nominativ singular, fonemul /c/ este urmat de desinenţele - $\varnothing$ şi -/e/. Exemple de radical terminat în /c/: oc-, ic-, perec-, vec-.

$/ \mathrm{J} /$

Fonemul $/ \mathrm{J} / \mathrm{cu}$ care se termină radicalul nominal apare mai ales singur în poziţie postvocalică la substantive masculine (UGHI), la substantive eterogene (PRIVEGHI), la cele feminine (LEGHE) şi la adjective (MEHENGHI). Unicul grup final complex care este posibil în această poziţie, şi anume $/ \mathrm{nJ} /$, caracterizează substantive masculine şi eterogene (SFINGHE, UNGHI). La nominativ singular, fonemul / / $/$ este urmat de desinenţele - $\varnothing$ şi -/e/. Exemple de radical terminat în / $/ \mathrm{J}$ : uf-, prives-, lej-, meheny-.

$/ \mathrm{k} /$

Radicalul nominal terminat în $/ \mathrm{k} /$ singur în poziţie postvocalică şi făcând parte din grupurile complexe $/ \mathrm{lk} /, / \mathrm{nk} /, / \mathrm{rk} /$, şi /sk/, se identifică la substantive masculine (ESCROC, MELC, PRUNC, TURC, VÂSC), la substantive eterogene (VEAC, CALC, TANC, ARC, DISC), la cele feminine (POTECĂ, GÂLCĂ, BANCĂ, MARCĂ, BROASCĂ) şi la adjective (SEC, BISULC, ADÂNC, TURC, FANTASC). Grupul final complex /jk/ caracterizează substantive masculine (TAICĂ) şi feminine (GRECOAICĂ) şi adjectivele (NĂTĂROAIC Ă), iar grupul $/ \mathrm{Jk} /$ substantive eterogene şi feminine (CHIOŞC; FLEAŞCĂ). Pe de altă parte, grupurile finale /tk/, /fk/, /mk/, /pk/ şi /tsk/

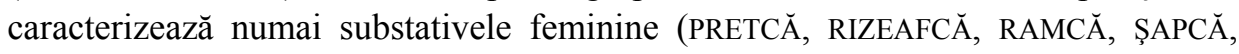


RAŢCĂ). La nominativ singular, fonemul /k/ este urmat de desinenţele - $\varnothing$ şi -/ə/. Exemple de radical terminat în /k/: eskrok-, veak-, potek-, sek-.

$$
/ \mathrm{g} /
$$

Radicalul nominal terminat în /g/ singur în poziţie postvocalică şi făcând parte din grupurile complexe $/ \mathrm{ng} /$ şi $/ \mathrm{rg} /$, se identifică la substantive masculine (COLEG, DIFTONG, ERG), la substantive eterogene (CÂşTIG, RANG, TÂRG), la cele feminine (VERIGĂ, CREANGĂ, VERGĂ) şi la adjective (DRAG, STÂNG, LARG). Grupul final complex /lg/ caracterizează toate cele trei clase generice ale substantivelor: FULG la substantive masculine, VULG la substantive eterogene şi ALGĂ la cele feminine. Grupul /zg/ caracterizează substantive masculine (PELASG) şi feminine (MÂZGĂ), precum şi adjectivele (PELASG). Grupul $/ \mathrm{vg} /$ apare ca excepţie la substantive feminine (TIVGĂ). La nominativ singular, fonemul /g/ este urmat de desinenţele -Ø şi -/ə/. Exemple de radical terminat în /g/: koleg-, kiftig-, verig-, drag-.

\section{/ts/}

Radicalul nominal terminat în /ts/ singur în poziţie postvocalică şi făcând parte din grupurile complexe /lts/ şi /rts/, se identifică la substantive masculine (SOT, COLT, GHIBORTT), la substantive eterogene (BRAȚ, ŞPALT, DOVORT), la cele feminine (AŢĂ, SALŢĂ, FORŢূ) şi la adjective (GLUMEȚ, DESCULȚ, TERȚ). Grupul final complex /nts/ caracterizează toate cele trei clase generice ale substantivelor: SPÂNȚ la substantive masculine, LANȚ la substantive eterogene şi VACANŢă la cele feminine. Grupul /mts/, la rândul lui, caracterizează substantive masculine (NEAMȚ) şi eterogene (SIMT) ). Grupul /jts/ caracterizează substantive eterogene şi feminine (BAIȚ; STRAIȚĂ), iar grupul /pts/ numai substantive feminine (CEAPȚĂ). La nominativ singular, fonemul /ts/ este urmat de desinenţele - $\varnothing$ şi -/ə/. Exemple de radical terminat în /ts/: sots-, brats-, ats-, glumets-.

\section{$/ \mathrm{t}^{\mathrm{j} /}$}

Radicalul nominal terminat în $/ \mathrm{t}^{\mathrm{j}} /$ singur în poziţie postvocalică şi făcând parte

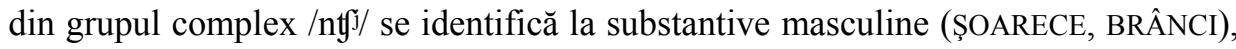
la substantive eterogene (FOARFECE, CORDENCI), la cele feminine (VOCE, LANCE) şi la adjective (TENACE, PONCE). Grupul final complex /1tji/ caracterizează substantive eterogene (BÂLCI) şi feminine (SALCE), precum şi adjectivele (DULCE), iar grupul $/ \mathrm{rg} \mathrm{J}^{\mathrm{J} /}$ caracterizează numai substantive masculine (SPÂRCI) şi eterogene (ZGÂRCI). La nominativ singular, fonemul $/ \mathrm{f}^{\mathrm{j} /} / \mathrm{este}$ urmat de desinenţele - $\varnothing$ şi -/e/. Exemple de

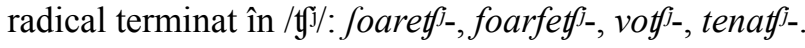

$$
/ \mathrm{d}^{\mathrm{j} /}
$$

Radicalul nominal terminat în /ḑ3/singur în poziţie postvocalică apare numai la substantive masculine (REGE) şi la cele feminine (LEGE). Făcând parte din grupul 


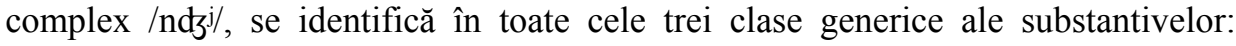
SPORANGE la substantive masculine, SÂNGE la substantive eterogene şi MINGE la cele feminine. Sub unele condiţii se poate accepta şi radicalul terminat în $/ \mathrm{ndz̧}^{\mathrm{j}} /$ şi în clasa adjectivelor (PURSÂNGE). Grupul final complex /ldzj/ caracterizează substantive eterogene şi feminine (GIULGI; HELGE). La nominativ singular, fonemul $/ \mathrm{d}^{\mathrm{j} /} / \mathrm{este}$ urmat de desinenţele - $\varnothing$ şi -/e/. Exemple de radical terminat în $/ \mathrm{dz}^{\mathrm{j}} /$ red $^{j}{ }^{j}$, $\operatorname{sind}^{j_{-}}$, ledj $_{-}^{j_{-}}$, pursind $^{j_{-}}$.

\section{CONCLUZII}

Din toate tipurile morfonologice de radical nominal prezentate detaliat mai sus, numai unele provoacă restricţii în alegerea alomorfelor sufixale (desinenţiale). Importante din acest punct de vedere sunt mai ales douăsprezece tipuri: radicali terminaţi cu orice vocală afară de $/ u /$, radicali terminaţi cu vocala $/ u /$, radicali terminaţi cu una dintre consoanele $/ \mathrm{j} /, / \mathrm{l} /, / \mathrm{r} /, / \mathrm{c} /, / \mathrm{J} /, / \mathrm{k} /, / \mathrm{g} /, / \mathrm{t} \mathrm{j} / /$ şi $/ \mathrm{d}^{\mathrm{j}} \mathrm{j} /$, şi - în fine radicali terminaţi cu orice consoană afară de cele enumerate înainte. Unele dintre cele nouă tipuri consonantice distinse pot fi unite, la râdul lor, în ansamblurile următoare: 1) radicali terminaţi cu semivocala $/ \mathrm{j} /$; 2) radicali terminaţ̧i cu consoanele lichide $\left./ 1 / \mathrm{şi} / \mathrm{r} /\left(\mathrm{C}_{\mathrm{L}}\right) ; 3\right)$ radicali terminaţi cu consoanele palatale $/ \mathrm{c} /$, /J/, $/ \mathrm{tg}^{\mathrm{j}} /$ şi $\left./ \mathrm{d}^{\mathrm{j}} /\left(\mathrm{C}_{\mathrm{P}}\right) ; 4\right)$ radicali terminaţi cu consoanele velarele $/ \mathrm{k} /$ şi $/ \mathrm{g} /\left(\mathrm{C}_{\mathrm{V}}\right)$. În cazul radicalilor terminaţi cu $\mathrm{C}_{\mathrm{L}}$, contează şi statutul fonologic al segmentului precedent, pertinente în această poziţie fiind numai consoanele $\left(\mathrm{CC}_{\mathrm{L}}\right)$. Pe această cale, se ajunge, în cele din urmă, la distingerea următoarelor şapte tipuri morfonologice de radical nominal relevante sub aspectul restricţiilor sintagmatice (,,R” simbolizează aici radicalul, iar „Nm” - tipul morfonologic nemarcat al finalei acestuia):

$$
\mathrm{R} / \mathrm{V}_{\mathrm{Nm}} /-
$$

Este tipul de radical cu finala vocalică nemarcată, adică radicalul terminat cu orice vocală afară de /u/. În acest tip se înscriu radicalii R/i/-, R/ìt-, R/e/-, R/o/-, R/o/-, R/a/-, de exemplu: besti- (BESTIE), osmanli- (OSMANLÂU), ese- (ESEU), kado(CADOU), tfiaxlo- (CEAHLĂU), gata- (GATA).

\section{$\mathrm{R} / \mathrm{u} /-$}

Este tipul de radical cu finala vocalică marcată, adică radicalul terminat în /u/, de exemplu: moru- (MORUă).

$$
\mathrm{R} / \mathrm{C}_{\mathrm{Nm}} /-
$$

Este tipul de radical cu finala consonantică nemarcată, adică radicalul terminat cu orice consoană afară de consoanele $/ \mathrm{j} /, / 1 /, / \mathrm{r} /, / \mathrm{c} /, / \mathrm{J} /, / \mathrm{k} /, / \mathrm{g} /, / \mathrm{fg} / / \mathrm{s}_{1} / \mathrm{d}^{3} \mathrm{j} /$. În acest tip se înscriu radicalii R/m/-, R/n/-, R/f/-, R/v/-, R/s/-, R/z/-, R/S/-, R/3/-, R/x/-, R/p/-, 
R/b/-, R/t/-, R/d/-, R/ts/-, de exemplu: num- (NUME), tren- (TREN), praf- (PRAF), elev- (ELEV), kas- (CASĂ), kaz- (CAZ), lenef- (LENEŞ), garaz- (GARAJ), vazdux(VĂZDUH), nisip- (NISIP), furub- (ŞURUB), retset- (REȚETÃ), umed- (UMED), brats(BRAȚ).

$$
\mathrm{R} / \mathrm{j} /-
$$

Este tipul de radical cu finala consonantică marcată $/ \mathrm{j} /$, de exemplu kraj- (CRAI).

$$
\mathrm{R} / \mathrm{CC}_{\mathrm{L}} /-
$$

Este tipul de radical cu finala consonantică marcată, adică radicalul terminat cu o consoană lichidă $/ 1 /$ sau $/ \mathrm{r} /$, precedată de o altă consoană, de exemplu: arbitr(ARBITRU), egzempl- (EXEMPLU).

$$
\mathrm{R} / \mathrm{C}_{\mathrm{P}} /-
$$

Este tipul de radical cu finala consonantică marcată palatală, adică radicalul terminat cu o palatală oclusivă sau africată din seria $/ \mathrm{c} /, \mathrm{IJ}_{\mathrm{J}} /, / \mathrm{tg} \mathrm{j} / \mathrm{s}$ s $/ \mathrm{d}^{\mathrm{j}} \mathrm{j} /$ de exemplu: vec- (VECHI), lej- (LEGHE), votj- (VOCE), redj ${ }^{j-}$ (REGE).

$$
\mathrm{R} / \mathrm{C}_{\mathrm{V}} /-
$$

Este tipul de radical cu finala consonantică marcată velară $/ \mathrm{k} / \mathrm{sau} / \mathrm{g} /$, de exemplu: eskrok- (ESCROC), koleg- (COLEG).

Relevanţa majorităţii tipurilor distinse este aproape absolută, deşi restricţiile sintagmatice pe care le provoacă finalele vocalice, mai ales segmentele /o/ şi /a/, sunt variate şi nu pot duce la stabilirea unor reguli fixe şi obligatorii. Pe de altă parte, relevanţa finalei semivocalice /j/ este dependentă de caracterul segmentului fonologic care o precedă, cât şi de subclasa unităţilor lexicale nominale: 1. în clasa adjectivelor, nerelevant este radicalul terminat cu /j/ care urmează după o altă consoană, de exemplu propj- (PROPRIU); 2. în clasa substantivelor eterogene, tipul $\mathrm{R} / \mathrm{j} /$ - nu este apropape deloc relevant afară de câteva excepţii, ca de exemplu portcej- (PORTCHEI); 3. în clasa substantivelor masculine, nu este relevant în toate cazurile radicalul terminat în $/ \mathrm{j} /$ având o consoană în poziţia penultimă, ca de exemplu nuntsj- (NUNŢIU). Ultimul tip, adică $\mathrm{R} / \mathrm{Cj} /-$, provoacă însă restricţii sintagmatice la substantive de tipul PUŞTI şi COVALI. Spre deosebire de clasele amintite mai sus, clasa substantivelor feminine conţine unităţi lexicale la care radicalul terminat în $/ \mathrm{j} /$ este relevant în toate cazurile. Tipurile morfonologice de radical flexionar distinse aici trebuie comparate cu cele care determină şi flexiunea verbală. Se poate presupune că şi în acest domeniu va fi valabilă, cel puţin în linii mari, distingerea a şapte tipuri stabilite în flexiunea nominală. 


\section{BIBLIOGRAFIE}

Cotennu, I. (ed.). (1985): Limba română contemporană. Fonetica. Fonologia. Morfologia. Bucureşti: Editura Didactică şi Pedagogică.

CyChNerski, T. (2001): Morfonologia limbii române. I. Paradigmatica. O abordare teoretică pe baza materialului verbal. Studia Romanica Posnaniensia, XXVIII: 17-22.

CYCHNERSKI, T. (2003): Morfonologia limbii române. II. Sintagmatica. O abordare teoretică pe baza materialului verbal. Studia Romanica Posnaniensia, XXIX: 139-148.

Guțu-Romalo, V. (1968): Morfologie structurală a limbii române. Substantiv, adjectiv, verb. Bucureşti: Editura Academiei R.S.R.

Guţu-Romalo, V. (coord.). (2008): Gramatica limbii române. Bucureşti: Editura Academiei Române.

IORDAN, I.; RoBU, V. (1978): Limba română contemporană. Bucureşti: Editura Didactică şi Pedagogică.

IRIMIA, D. (2000): Gramatica limbii române. Iaşi: Editura Polirom.

PANĂ Dindelegan, G. (coord.). (2010): Gramatica de bază a limbii române. Bucureşti: Univers Enciclopedic Gold.

SALA, M. (coord.). (2001): Enciclopedia limbii române. Bucureşti: Editura Univers Enciclopedic.

VASILIU, E. (1965): Fonologia limbii române. Bucureşti: Editura Ştiinţifică.

VINTILĂ-RĂDULESCU, I. (coord.). (2005): Dicţionarul ortografic, ortoepic şi morfologic al limbii române. Bucureşti: Univers Enciclopedic.

VINTILĂ-RĂDULESCU, I. (2009): Dicţionar normativ al limbii române ortografic, ortoepic, morfologic şi practic. Bucureşti: Corint. 